NATURAL DRUGS

\title{
PHYTOESTROGENS USE BY POLISH WOMEN
}

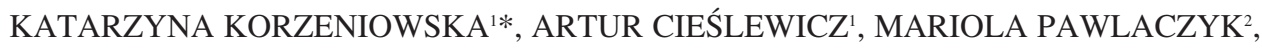 \\ MICHAŁ PAWLACZYK ${ }^{3}$ and ANNA JABŁECKA ${ }^{1}$
}

\author{
${ }^{1}$ Department of Clinical Pharmacology, Poznan University of Medical Sciences, Poland \\ ${ }^{2}$ Department of Geriatric Medicine and Gerontology, Poznan Univerity of Medical Sciences \\ ${ }^{3}$ Department of Gynaecology and Obstetrics, District Hospital of Szamotuly
}

\begin{abstract}
The aim of the study was to evaluate knowledge about phytoestrogens among Polish menopausal women, and to assess their applicability and safety. The study included 300 women from the Wielkopolska Region, aged 40-60 years. The questionnaire was designed especially for the study. Crosstabulation tables and Pearson's chi-squared test was used for the statistical analysis. 147 respondents continued to menstruate. Hormone Replacement Therapy was used by 69 subjects; 114 respondents, used phytoestrogens. The place of inhabitance influenced the reasons for not using phytoestrogens. Media, healthcare providers, and personnel were the main sources of information about phytoestrogens. Most of the respondents perceived phytoestrogens as substances displaying a beneficial effect on health. $69 \%$ of the subjects reported positive effects of non-hormonal preparations for the relief of climacteric symptoms, mainly reduction in hot flushes and alleviation of joint pain. Our results support the postulate of efficacy and safety of phytoestrogen use to relieve climacteric symptoms. Both education and place of inhabitance appear to affect the opinions of the affected females about phytoestrogen use during menopause.
\end{abstract}

Keywords: climacteric symptoms, HRT, menopause, phytoestrogens, survey study

\section{Phytoestrogens and menopause in the life of Po- lish women}

In the past, average female life expectancy was too short for most women to actually reach the climacteric period. It was not until the $20^{\text {th }}$ century that their lifespan expanded enough for the women to enter menopause. Previously menopause heralded the beginning of old age, whereas nowadays it is yet another, albeit groundbreaking, phase of a woman's life which signals the onset of the climacteric period. The few years preceding the last menstrual period are commonly called pre-menopause. During that time the female body produces a steadily diminishing amount of sex hormones, necessary to maintain the menstrual cycle. The decrease in hormone concentration occurs gradually and triggers a set of symptoms that herald the onset of menopause, the most significant being a change in the menstrual rhythm, leading to complete cessation of menstruation. Owing to hormone deficit, these changes are accompanied by a wide range of adverse effects known as the climacteric symptoms. Many women experience hot flashes, paroxysmal sweats, somnipathy, and headaches.
Climacteric women are often easily irritable and complain of mood swings, crying spells, loss of concentration and deteriorating memory (1-5).

The World Health Organization (WHO) defines menopause as permanent cessation of menstruation after 12 consecutive months of amenorrhea. Mean age at menopause in Poland is estimated at 50 years. Menopause below the age of 40 and over the age of 69 is considered as an abnormal occurrence (6-7).

Perimenopause (a few years preceding the menopause and 12 months afterwards) and postmenopause both constitute a challenging period of time for a great number of women. Hormone Replacement Therapy (HRT) is one of the recommended methods to relieve climacteric symptoms and to lower their intensity. Despite its unquestionable benefits, e.g. a positive effect on the cardiovascular system and prevention of bone mineral density loss, approximately $70 \%$ of HRT users are estimated to discontinue treatment after about one year (8-9).

The main reasons rest in the occurrence of irregular bleeding, breast tenderness and pain (mastalgia),

$\bar{*}$ Corresponding author: e-mail: kkorzeniowska@ump.edu.pl 
nausea, migraines, weight gain, edema due to fluid retention, and fear of breast cancer (10-13).

Side effects of HRT motivate a large group of women to apply more natural methods of treatment - plant-derived preparations (mostly phytoestrogens). The method is also recommended in cases of absolute contraindications to HRT (14-15).

The life expectancy of an average Polish woman continues to rise - mean number of years for the 0 age group has risen from 61.7 years in 1950 to 81 years in 2012 (16). Thus, it seems safe to assume that about $1 / 3$ of the adult life of an average female will fall on the period after the menopause. Consequently, many women will experience the climacteric syndrome, in a varying degree of intensity and will also suffer from plenty long-term consequences of low estrogen state.

\section{Objectives}

In presents article, a survey study on the safety and efficacy of phytoestrogen use was conducted to investigate whether Polish women use natural methods of alleviating the climacteric symptoms.

\section{MATERIAL AND METHODS}

Our survey study was carried out in a group of 300 women, at age greater or equal than 40 years, patients of outpatient clinics and clients of-pharmacies, inhabitants of the Wielkopolska Region. An original questionnaire, consisting of 20 questions (mostly single- or multiple-answer closed ones), was the investigation tool. All answers were offered and the respondents could not extend beyond them. The survey also included half-open questions, with the 'others' entry that allowed the respondents to submit their own opinion if it was not included among the offered answers. Examples of openended questions, where the respondents are required to present their subjective views, were less numerous. The questionnaire also included the demographics section, allowing to determine respondent age, education, place of residence and BMI (Body Mass Index). Crosstabulation tables and Pearson's chi-squared test (with $p=0.05$ as statistical significance threshold) were used to evaluate statistically significant differences between studied groups.

\section{RESULTS}

The characteristic of the respondents is presented in Table 1, while the results of the survey and statistical analysis are presented in Tables 2 and 3. A total of 300 women, aged 40-60 years, with tertiary, secondary and basic vocational education (100 in each education group) were recruited for the study. Most of the respondents were city dwellers (183 women, 61\%). Out of all women, 147 continued to menstruate. The patients mostly complained about cardiovascular system diseases.

HRT was used by $69(23 \%)$ subjects. There was a statistically significant difference $(p<0.05)$ in HRT use between women with basic vocational and secondary education: the former used HRT significantly less often than the latter. The main reason for not using HRT reported by the respondents was lack of the need to use it (45\%) and the fear of potential complications accompanying HRT use reported by $25 \%$ of the women.

A statistically significant difference between village and city dwellers was noted: the former significantly less often $(p<0.05)$ reported lack of need

Table 1. Characteristic of the respondents.

\begin{tabular}{|l|c|}
\hline Parameter & Value \\
\hline Age $[$ years] & $49.9 \pm 6.0$ \\
\hline BMI $\left[\mathrm{kg} / \mathrm{m}^{2}\right]$ & $24.3 \pm 2.9$ \\
\hline Age of menstruation cessation [years] & $49.1 \pm 3.2$ \\
\hline Number of women with menstruation ceased & $153(51 \%)$ \\
\hline Frequency of diagnosed diseased: & \\
\hline cardiovascular diseases & $57 \%$ \\
\hline central nervous system diseases & $29 \%$ \\
\hline thyroid diseases & $21 \%$ \\
\hline diabetes & $17 \%$ \\
\hline osteoporosis & $11 \%$ \\
\hline cancer & $7 \%$ \\
\hline
\end{tabular}


Table 2. Summary of participants answers for the survey.

\begin{tabular}{|c|c|c|c|c|c|c|}
\hline & \multirow{2}{*}{$\begin{array}{l}\text { All } \\
\text { respondents }\end{array}$} & \multicolumn{2}{|c|}{ Dwelling place } & \multicolumn{3}{|c|}{ Education } \\
\hline & & Urban & Rural & Basic vocational & Secondary & Tertiary \\
\hline Number of respondents & 300 & 183 & 117 & 100 & 100 & 100 \\
\hline \multicolumn{7}{|l|}{ HRT } \\
\hline Percentage of women using HRT & $23 \%$ & $20 \%$ & $27 \%$ & $18 \%$ & $30 \%$ & $21 \%$ \\
\hline Percentage of women not using HRT & $77 \%$ & $80 \%$ & $73 \%$ & $82 \%$ & $70 \%$ & $79 \%$ \\
\hline \multicolumn{7}{|l|}{ Reasons for not using HRT } \\
\hline No need & $45 \%$ & $51 \%$ & $34 \%$ & $48 \%$ & $42 \%$ & $44 \%$ \\
\hline Afraid of adverse effects & $25 \%$ & $22 \%$ & $30 \%$ & $24 \%$ & $27 \%$ & $25 \%$ \\
\hline Other reasons & $6 \%$ & $5 \%$ & $7 \%$ & $7 \%$ & $1 \%$ & $10 \%$ \\
\hline No information on HRT & $1 \%$ & $1 \%$ & $2 \%$ & $3 \%$ & $0 \%$ & $0 \%$ \\
\hline \multicolumn{7}{|l|}{$\begin{array}{l}\text { Main sources of information about } \\
\text { phytoestrogens }\end{array}$} \\
\hline Mass media & $47 \%$ & $52 \%$ & $39 \%$ & $49 \%$ & $38 \%$ & $54 \%$ \\
\hline Health care employee & $41 \%$ & $41 \%$ & $41 \%$ & $39 \%$ & $44 \%$ & $40 \%$ \\
\hline Internet & $9 \%$ & $5 \%$ & $15 \%$ & $9 \%$ & $13 \%$ & $5 \%$ \\
\hline Friends & $3 \%$ & $2 \%$ & $5 \%$ & $3 \%$ & $5 \%$ & $1 \%$ \\
\hline \multicolumn{7}{|l|}{$\begin{array}{l}\text { Associations aroused by the term } \\
\text { 'phytoestrogens' }\end{array}$} \\
\hline Compounds with positive effects & $51 \%$ & $60 \%$ & $37 \%$ & $43 \%$ & $51 \%$ & $59 \%$ \\
\hline Compounds with negative effects & $28 \%$ & $25 \%$ & $32 \%$ & $30 \%$ & $31 \%$ & $23 \%$ \\
\hline $\begin{array}{l}\text { Lack of knowledge Concerning } \\
\text { phytoestrogens }\end{array}$ & $13 \%$ & $10 \%$ & $18 \%$ & $21 \%$ & $8 \%$ & $10 \%$ \\
\hline Fear & $8 \%$ & $5 \%$ & $13 \%$ & $6 \%$ & $10 \%$ & $8 \%$ \\
\hline \multicolumn{7}{|l|}{ Diet } \\
\hline $\begin{array}{l}\text { Percentage of women using dietary } \\
\text { supplements containing phytoestrogens }\end{array}$ & $38 \%$ & $32 \%$ & $47 \%$ & $37 \%$ & $38 \%$ & $39 \%$ \\
\hline $\begin{array}{l}\text { Percentage of women who are willing } \\
\text { to introduce food containing } \\
\text { phytoestrogens into daily diet }\end{array}$ & $68 \%$ & $66 \%$ & $71 \%$ & $54 \%$ & $81 \%$ & $69 \%$ \\
\hline \multicolumn{7}{|l|}{ Skin } \\
\hline $\begin{array}{l}\text { Percentage of women who know about } \\
\text { the effect of phytoestrogens on skin }\end{array}$ & $43 \%$ & $39 \%$ & $50 \%$ & $11 \%$ & $53 \%$ & $65 \%$ \\
\hline
\end{tabular}

to use HRT but significantly more often $(\mathrm{p}<0.05)$ mentioned the fear of adverse effects. In case of the three different education groups, the only statistically significant difference $(p<0.01)$ regarding the 'others' section was observed between the secondary and tertiary education groups of respondents.

The respondents were asked about using phytoestrogens to alleviate climacteric symptoms. 114 (38\%) women confirmed the use of non-hormonal components in the form of dietary supplements for this purpose (68 took preparations with soy phytoestrogens, 19 - a combination of soy and hop phytoestrogens, 27 - a combination of soy, hop and flax phytoestrogens; see Table 4 for details.). Average isoflavone content in the preparations was $46.67 \pm$
$7.49 \mathrm{mg}$. A statistically significant difference was observed between village and city dwellers: the former significantly more often $(p<0.05)$ used dietary supplements containing phytoestrogens.

Mass media (radio, TV, press) and recommendations of healthcare providers and personnel (doctors, pharmacists, nurses, dieticians) were the main sources of information about phytoestrogens reported by the respondents. Statistically significant differences were noted between village and city dwellers: the former mentioned mass media (radio, $\mathrm{TV}$, literature; $\mathrm{p}<0.05$ ) less often and the Internet more often $(\mathrm{p}<0.01)$, as compared to the latter. As far as different education groups were concerned, statistically significant differences were observed 
between women with secondary and tertiary education: the latter mentioned mass media significantly more frequently $(\mathrm{p}<0.05)$ than the Internet $(\mathrm{p}<$ $0.05)$.

The majority of respondents $(51 \%)$ associated the term 'phytoestrogens' with substances beneficial for their health. Statistically significant differences were noted between village and city dwellers: the former reported positive associations less often $(\mathrm{p}<$ 0.001 ), but more often mentioned no knowledge about the term itself $(\mathrm{p}<0.05)$, and their concerns ( $\mathrm{p}$ $<0.05$ ). Also, statistically significant differences were discovered between education groups. Respondents with basic vocational education were not familiar with the term 'phytoestrogens' more often than women with secondary $(\mathrm{p}<0.01)$ and ter- tiary $(\mathrm{p}<0.05)$ education and less often perceived phytoestrogens as compounds having a beneficial effect $(\mathrm{p}<0.05)$.

A total of $68 \%$ subjects $(n=204)$ declared their willingness to introduce dietary products containing phytoestrogens into their daily diet, city and village dwellers alike and in comparable numbers. However, a statistically significant difference was observed as far as education was concerned. Women with basic vocational education were less willing to alter their diet than respondents with secondary $(\mathrm{p}<$ $0.001)$ and tertiary $(\mathrm{p}<0.05)$ education.

Knowledge of phytoestrogen effects on the condition of the skin was declared by 129 women (43\%). The percentage was comparable among city and village dwellers, although a statistically signifi-

Table 3. Analysis of statistical significance of differences in answers obtained in different subgroups. Pearson's chi-squared test (with $\mathrm{p}=0.05$ as the statistical significance threshold) was used to evaluate statistical significance. Yates correction for continuity was used when necessary (expected count $<5$ ).

\begin{tabular}{|c|c|c|c|c|}
\hline & \multirow{2}{*}{$\begin{array}{l}\text { Dwelling place } \\
\text { Urban vs rural }\end{array}$} & \multicolumn{3}{|c|}{ Education } \\
\hline & & $\begin{array}{c}\text { Basic } \\
\text { vocational vs } \\
\text { secondary }\end{array}$ & $\begin{array}{c}\text { Basic } \\
\text { vocational vs } \\
\text { tertiary }\end{array}$ & $\begin{array}{c}\text { Secondary } \\
\text { vs } \\
\text { tertiary }\end{array}$ \\
\hline \multicolumn{5}{|l|}{ HRT } \\
\hline No. of women using HRT & n.s. & $*$ & n.s. & n.s. \\
\hline \multicolumn{5}{|l|}{ Reasons for not using HRT } \\
\hline No need & $*$ & n.s. & n.s. & n.s. \\
\hline Afraid of adverse effects & $*$ & n.s. & n.s. & n.s. \\
\hline Other reasons & n.s. & n.s. $\dagger$ & n.s. & $* *$ \\
\hline No information on HRT & n.s. & n.s. & n.s. & n.s. \\
\hline \multicolumn{5}{|l|}{ Main sources of information about phytoestrogens } \\
\hline Mass media & $*$ & n.s. & n.s. & $*$ \\
\hline Healthcare employee & n.s. & n.s. & n.s. & n.s. \\
\hline Internet & $* *$ & n.s. & n.s. & $*$ \\
\hline Friends & n.s. $\dagger$ & n.s. $\dagger$ & n.s. $\dagger$ & n.s. \\
\hline \multicolumn{5}{|l|}{ Associations aroused by the term 'phytoestrogens' } \\
\hline Compounds with positive effects & $* * *$ & n.s. & * & n.s. \\
\hline Compounds with negative effects & n.s. & n.s. & n.s. & n.s. \\
\hline Lack of knowledge concerning phytoestrogens & $*$ & $* *$ & $*$ & n.s. \\
\hline Fear & $*$ & n.s. & n.s. & n.s. \\
\hline \multicolumn{5}{|l|}{ Diet } \\
\hline $\begin{array}{l}\text { No. of women using dietary supplements } \\
\text { containing phytoestrogens }\end{array}$ & $*$ & n.s. & n.s. & n.s. \\
\hline $\begin{array}{l}\text { No. of women who are willing to introduce } \\
\text { food containing phytoestrogens into daily diet }\end{array}$ & n.s. & $* * *$ & $*$ & n.s. \\
\hline \multicolumn{5}{|l|}{ Skin } \\
\hline $\begin{array}{l}\text { No. of women who know about the effect } \\
\text { of phytoestrogens on skin }\end{array}$ & n.s. & $* * *$ & $* * *$ & n.s. \\
\hline
\end{tabular}

n.s. - non-significant; $*-\mathrm{p}<0.05 ; * *-\mathrm{p}<0.01 ; * * *-\mathrm{p}<0.001 ; \dagger-$ Yates correction used 
Table 4. Phytoestrogen preparations used by the respondents.

\begin{tabular}{|l|c|c|c|c|}
\hline Preparation & $\begin{array}{c}\text { Isoflavone } \\
\text { content [mg] }\end{array}$ & Dosing & $\begin{array}{c}\text { Average duration of } \\
\text { treatment [months] }\end{array}$ & $\begin{array}{c}\text { Number of } \\
\text { patients }\end{array}$ \\
\hline soy & 50 & once per day & $11.8 \pm 9.9$ & 68 \\
\hline soy + hop & 30 & once per day & $11.4 \pm 7.9$ & 19 \\
\hline soy + hop + flax & 50 & once per day & $12.6 \pm 8.6$ & 27 \\
\hline Average & $46.67 \pm 7.49$ & - & $11.9 \pm 9.2$ & - \\
\hline
\end{tabular}

Table 5. Number of women reporting climacteric symptoms before and after the use of phytoestrogens. Pearson's chi-squared test was used to evaluate the statistical significance of differences.

\begin{tabular}{|l|c|c|c|c|}
\hline \multicolumn{1}{|c|}{ Symptom } & $\begin{array}{c}\text { Before use of } \\
\text { phytoestrogens }\end{array}$ & $\begin{array}{c}\text { After use of } \\
\text { phytoestrogens }\end{array}$ & $\begin{array}{c}\text { Percentage of women } \\
\text { with symptoms relieved }\end{array}$ & $\begin{array}{c}\text { Statistical } \\
\text { significance }\end{array}$ \\
\hline Flushing & 87 & 40 & $54.02 \%$ & $\mathrm{p}<0.001$ \\
\hline Headache and dizziness & 62 & 36 & $41.94 \%$ & $\mathrm{p}<0.001$ \\
\hline Tiredness & 60 & 31 & $48.33 \%$ & $\mathrm{p}<0.001$ \\
\hline Hyperhidrosis & 81 & 24 & $70.37 \%$ & $\mathrm{p}<0.001$ \\
\hline Athralgia & 61 & 18 & $57.03 \% \pm 12.96 \%$ & $\mathrm{p}<0.001$ \\
\hline
\end{tabular}

cant difference was observed between groups with different level of education. The knowledge of phytoestrogen effect on the skin was significantly smaller $(p<0.001)$ among women with basic vocational education as compared to respondents with secondary and tertiary education.

The subsequent questions were addressed only to those respondents $(n=114)$ who reported the use of non-hormonal substances for climacteric symptom alleviation. The participants have been taking preparations with isoflavones content $30-50 \mathrm{mg}$ (Table 4) for one year averagely (11.9 \pm 9.2 months). They reported a positive effect of phytoestrogens on such symptoms as flushing, headache and dizziness, tiredness, hyperhidrosis and arthralgia (Table 5). Depending on the symptom, $41.94 \%$ to $70.49 \%$ of respondents taking phytoestrogens reported improvements $(57.03 \% \pm 12.96 \%$ on average). Furthermore, $81 \%$ of the study participants positively assessed the safety of phytoestrogen use. 22 respondents (19\%) reported mild adverse effects associated with the gastrointestinal tract, including heartburn, abdominal pain, nausea, constipation, diarrhea, lack of appetite and flatulence.

\section{DISCUSSION}

Health and emotional perimenopausal problems affect millions of women worldwide. Current demographic data indicate that approximately 25 million women enter menopause every year. WHO studies demonstrate a notable rise in the population of women at the age of 50 and more. It is estimated that by 2030 women from that age group will have constituted over $20 \%$ of the entire population. A steady increase in female life expectancy is the reason why a growing number of women experience menopause and why about one-third of their life will fall on the time after the menopause $(6,17)$.

Mean age at menopause varies, depending on geographical location, and ranges from 42.1-49.5 years in Asia, 43.8-53.0 in Latin America, 50.5-51.4 in Northern America, and 50.1-52.8 in Europe (18). In our population, observed mean age at last menstruation was slightly below the mean age for the European population. The age at menopause is affected by a number of factors, with tobacco smoking, BMI > 30, and a small amount of physical activity as stimulatory factors and multiparity as an inhibitory factor (17).

WHO experts differentiate between specific and non-specific climacteric symptoms, typical for menopause and hormone-related. Irregular menstruation, vasomotor, and urogenital symptoms belong to the former group, whereas non-specific symptoms - in other words, those caused by other than hormonal changes - include depression, anxiety, insomnia, difficulty to concentrate, headaches, dizziness, backache, and energy deficiency. Economic, material, family, and professional situation, as 
well as education, aging, substance abuse and tobacco smoking, are among the non-hormonal factors that might trigger non-specific symptoms of menopause (19-22).

HRT is one of the most common methods to combat menopause-related complaints. Regardless, it continued to bring a considerable amount of controversy, especially after the results of the Women's Health Initiative (WHI), published in 2002, demonstrated lack of the beneficial effect of HRT on the cardiovascular system and elevated (by 26\%) risk for breast cancer. Subsequent results revealed that WHI study participants initiated HRT many years after the onset of menopause, thus constituting a failed attempt at secondary prevention. Moreover, an analysis of breast cancer cases and episodes of coronary disease demonstrated no increase in their number in the study group but a significant increase in the control group (23).

Recent clinical studies confirmed HRT efficacy in women of the early-menopause age (24-25). Such therapy significantly lowers the risk of heart failure but does not increase the risk of breast cancer or stroke (26).

Approximately 6-7\% of Polish menopausal women are estimated to use HRT, whereas in the Western countries the ratio ranges between $18-30 \%$. Furthermore, it has been emphasized that most HRT users are better educated and have higher socioeconomic status (27). In our studied population, HRT was used by $23 \%$ of the respondents, what amounted to a higher ratio than the average estimated for Poland. The result is most probably related to study location and that fact that an overwhelming majority of the study participants was recruited among residents of Poznań and neighboring towns, who had better access both, to information about HRT and medicines. Moreover, most of the inhabitants of villages close to Poznań are people working in the city and therefore cannot be treated as average representatives of a common rural environment. A similar result (19.8\% of the respondents) about HRT use was obtained among the population of Łódź (27). A correlation between HRT use and education was also confirmed. In our study, women with basic vocational education constituted a group of least frequent users of HRT.

Phytoestrogen use is another method of relieving climacteric symptoms as these plant-derived compounds may have a comparable effect to estrogens, owing to their structural similarity (28). However, the studies on phytoestrogen applicability in alleviation of menopausal symptoms are still in progress (28-29). Our results showed that averagely more than half of the respondents taking phytoestrogens reported improvements. Similar findings were demonstrated in the polish study investigating the efficacy of standardized soy isoflavone extract in a group of 169 women over the course of 12 months (30). The beneficial effect of isoflavones was also mentioned in other studies (31-37).

Phytoestrogen safety was positively evaluated by $81 \%$ of the respondents, whereas reported adverse effects (mild stomach and intestine complaints) were transient in nature, what is in agreement with results of other authors (33-35).

Phytoestrogen use in a form of dietary supplements was reported by $38 \%$ of our respondents, most frequently by village dwellers (probably due to easier access to such substances). Unlike hormonal preparations, phytoestrogens are prescription-free and commonly available in most pharmacies. Interestingly, positive associations with the term 'phytoestrogens' were declared by a significantly higher number of city dwellers as compared to their village peers. In fact, the latter significantly more often reported unfamiliarity with the term itself as compared to city inhabitants. Mass media were most commonly mentioned among sources of information about phytoestrogens, but differences correlated with a place of residence and education were observed. City dwellers with tertiary education significantly more often obtained knowledge about phytoestrogens from mass media than the Internet, as compared to village dwellers or women with secondary education. The difference might stem from the fact that the Internet is not perceived as a highly credible medium, especially within the medical circles, so women with tertiary education might have felt reluctant to reveal it as their source of information.

We also noted a significant influence of education on the readiness to introduce dietary products with phytoestrogens into the daily diet and the awareness of beneficial effect of phytoestrogens on the skin - in both cases women with basic vocational education were less willing to give an affirmative answer to these questions than their peers with secondary or tertiary education. Similarly, Hanna et al. (2010) in their study on isoflavone supplementation in Australian women revealed higher education qualifications in a group of women consuming food containing isoflavones (36).

\section{CONCLUSIONS}

1. Our results demonstrate efficacy and safety of phytoestrogens for relieving climacteric symptoms. 
2. Both, education and place of inhabitance affect the state of knowledge about phytoestrogens and their use.

3. Place of inhabitance does not affect the decision to use HRT but influences the decision to refrain from such treatment.

\section{Conflict of interest}

The authors declare no conflict of interest.

\section{REFERENCES}

1. Brockie J.: Nurs. Stand. 28, 48 (2013).

2. Griffiths A., MacLennan S.J., Hassard J.: Maturitas 76, 155 (2013).

3. Yazdi Z., Sadeghniiat-Haghighi K., Ziaee A., Elmizadeh K., Ziaeeha M.: Psychiatry J. 2013; 907068. Epub 2013 Nov 5.

4. Freeman E.W., Sammel M.D., Boorman D.W., Zhang R.: JAMA Psychiatry 71, 36 (2013).

5. Mirabi P., Mojab F.: Iran J. Pharm. Res. 12, 217 (2013).

6. Haddad G., Williams D.B.: In: Lewis V (ed.) Reproductive Endocrinology and Infertility. Landes Bioscience 2007.

7. Boughton M., Halliday L.: Health Soc. Care Community 16, 565 (2008).

8. Moore A.: J. Am. Assoc. Nurse Pract. 25, 126 (2013).

9. Hodis H.N., Mack W.J.: J. Steroid Biochem. Mol. Biol. 42, 68 (2013).

10. Tom S.E., Anderson M.L., Landis C.A., Bowles E.J., Woods N.F., Reed S.D. et al.: Menopause 18, 1184 (2011).

11. Jalava-Broman J., Mäkinen J., Ojanlatva A., Jokinen K., Sillanmäki L., Rautava P.: Acta Obstet. Gynecol. Scand. 90, 351 (2011).

12. Sahin N.H., Bal M.D., Boğa N.M., Gökdemirel S., Taşpınar A.: Climacteric 14, 152 (2011).

13. Newton K.M., Reed S.D., Grothaus L.C., La Croix A.Z., Nekhlyudov L., Ehrlich K., et al.: Menopause 17, 734 (2010).

14. Ye Y.B., Wang Z.L., Zhuo S.Y., Lu W., Liao H.F., Verbruggen M. et al.: Menopause 19, 791 (2012).

15. Mainini G., Torella M., Di Donna M.C., Esposito E., Ercolano S., Correa R. et al.: Clin. Exp. Obstet. Gynecol. 40, 337 (2013).

16. Rutkowska L. Life expectancy tables of Poland, 2012. Central Statistical Office, Warsaw,
Poland 2013. ISSN 1507-1340. http://www.stat. gov.pl/cps/rde/xbcr/gus/POP life expectancy in 2012.pdf (accessed on 06.06.2017).

17. Dratva J., Gómez Real F., Schindler C., Ackermann-Liebrich U., Gerbase M.W., ProbstHensch N.M. et al.: Menopause 16, 385 (2009).

18. Palacios S., Henderson V.W., Siseles N., Tan D., Villaseca P.: Climacteric 13, 419 (2010).

19. Bielawska-Batorowicz E.: Prz. Menopauzalny 1, 53 (2005).

20. Binfa L., Castelo-Branco C., Blümel J.E., Cancelo M.J., Bonilla H., Muńoz I. et al.: Maturitas 48, 425 (2004).

21. Politi M.C., Schleinitz M.D., Col N.F.: J. Gen. Intern. Med. 23, 1507 (2008).

22. Dew T.P, Williamson G.: Menopause 20, 1207 (2013).

23. Binkowska M., Jakiel G.: Prz. Menopauzalny 1, 1 (2013).

24. Bužgová R., Kanioková J.: Ceska Gynekol. 78, 420 (2013).

25. Utian W.H, Woods N.: Menopause 20, 1098 (2013).

26. Schierbeck L., Rejnmark L., Tofteng C., Stilgren L., Eiken P., Mosekilde L. et al.: BMJ 345, 6409 (2012).

27. Wyderka M., Zdziennicki A.: Prz. Menopauzalny 5, 317 (2006).

28. Borelli F., Edzard E.: Maturitas 66, 333 (2010).

29. Szkutnik-Fiedler D., Jedrzejczyk M., Grzeskowiak E., Bartkowiak-Wieczorek J., SeremakMrozikiewicz A. et al.: Ginekol. Pol. 81, 929 (2010).

30. Drews K., Seremak-Mrozikiewicz A., Puk E., Kaluba-Skotarczak A., Malec M., Kazikowska A.: Ginekol. Pol. 78, 307 (2007).

31. Czuczwar P., Paszkowski T., Lisiecki M., Woźniak S., Stępniak A.: Prz. Menopauzalny 16, 8 (2017)

32. Moore T.R., Franks R.B., Fox C.: J. Midwifery Womens Health 62, 286 (2017)

33. Drews K., Seremak-Mrozikiewicz A., Puk E., Kaluba-Skotarczak A., Malec M., Kazikowska A.: Ginekol. Pol. 78, 361 (2007).

34. Panay N.: Climacteric 14 Suppl. 2, 2 (2011).

35. Pusparini, Dharma R., Suyatna F.D., Mansyur M., Hidajat A.: Asia Pac. J. Clin. Nutr. 22, 357 (2013).

36. Hanna K.L., O’Neill S., Lyons-Wall P.M.: Asia Pac. J. Clin. Nutr. 19, 540 (2010).

Received: 09. 06. 2017 